\title{
FALTA DE HIPERCONECTIVIDAD EN LA CARRERA DE COMUNICACIÓN SOCIAL DE LA UNIVERSIDAD TÉCNICA DE BABAHOYO EXTENSIÓN QUEVEDO
}

\section{LACK OF HYPERCONECTIVITY IN THE CAREER OF SOCIAL COMMUNICATION OF THE TECHNICAL UNIVERSITY OF BABAHOYO EXTENSION QUEVEDO}

\begin{abstract}
Carla Valeria Carranza Muñoz, Mgs. Magíster en Comunicación Estratégica (Ecuador). Asistente Administrativa de la Universidad Católica de Santiago de Guayaquil, Ecuador. ccarranza@mgs.ecotec.edu.ec

Patricia Yajaira Jadán Solis, Mgs. Magíster en Comunicación Estratégica (Ecuador). Docente de la Universidad Técnica de Babahoyo Extensión Quevedo, Ecuador. paty_jad@hotmail.com
\end{abstract}

\section{ARTÍCULO DE INVESTIGACIÓN}

Recibido: 27 de septiembre de 2019.

Aceptado: 23 de diciembre de 2019.

\section{RESUMEN}

La investigación y el proceso del mismo, muestran los resultados de un estudio dirigido al tratamiento de la información y del desarrollo de las TIC, en la carrera de Comunicación Social, de la Universidad Técnica de Babahoyo-Extensión Quevedo. Tiene como objetivo determinar su rol en diferentes departamentos como entes mediadores entre el docente-estudiante. Se aportaron premisas básicas que debe tener en cuenta el claustro universitario para la formación de un comunicador social competente que responda a las demandas de la sociedad actual. Esto, se obtuvo a partir de la utilización de métodos empíricos como la observación, la entrevista, la encuesta; y métodos teóricos. Las TIC, actúan como intermediarios de relaciones de carácter bidimensional. Las autoras sintetizan poner en juego todas las competencias necesarias para lograr los flujos de la comunicación de una manera asertiva en la Universidad Técnica de Babahoyo Extensión Quevedo. 
Palabras claves: comunicación, imagen, interacción, tecnología de la información.

\section{ABSTRACT}

The research and its process show the results of a study aimed at the treatment of information and the development of ICTs in the Social Communication career, of the Technical University of Babahoyo-Extension Quevedo. Its objective is to determine its role in different departments as mediating entities among the teacher-student. Basic premises were provided that must be taken into account by the university faculty for the formation of a competent social communicator that responds to the demands of today's society. This was obtained from the use of empirical methods such as observation, interview, survey; and theoretical methods. The ICTs, act as intermediaries of two-dimensional relationships. The authors synthesize putting into play all the necessary competences to achieve communication flows in an assertive manner at the Technical University of Babahoyo Extension Quevedo.

Keywords: communication, image, interaction, information technology.

\section{INTRODUCCIÓN}

El presente estudio de investigación planteado por las autoras, tiene como objetivo diseñar un plan de estrategias de comunicación web, para fortalecer la interacción y difusión de la información, en tiempo real de las actividades y eventos de la carrera de Comunicación Social de la Universidad Técnica de Babahoyo extensión Quevedo.

Mediante el método descriptivo se identificó que esta institución necesita de una mejor gestión del manejo de la información que comparten y difunden con el personal administrativo, docentes y alumnos de la carrera de Comunicación Social, puesto que en la actualidad no se cuenta con App., disponibles para atender las necesidades, consultas y requerimientos de los usuarios clientes actuales y a futuro.

Para ello es importante hacerse la siguiente pregunta: ¿Existe una única definición de comunicación? Posiblemente cada uno de nosotros tenga una respuesta propia, pero ante esta 
interrogante, la respuesta es negativa; aunque quizás las más coincidentes pueden ser las siguientes (Tabla 1):

Tabla 1. Definición de Comunicación.

\section{COMUNICACIÓN ES:}

La capacidad que tiene todo ser animado de relacionarse con su entorno.

El intercambio de ideas o pensamientos entre dos o más personas.

Una manera de entrar en contacto con los demás; sin ella, no existirían las relaciones humanas.

Un conjunto de técnicas que permiten la difusión de mensajes escritos o audiovisuales a uno o varios públicos.

Un proceso bilateral, un circuito en el que interactúan y se interrelacionan dos o más personas, a través de un conjunto de signos o símbolos convencionales, por ambos conocidos.

Fuente: Diez (2011).

De todas estas definiciones se ha escogido la última, ya que en ella se encuentran los tres actores que confluyen en toda comunicación humana:

- Una persona que habla (emisor).

- Una persona que escucha (receptor).

- Lo que dice la persona que habla a la persona que escucha (mensaje).

Estos tres factores se relacionan entre sí a través de tres operaciones:

- Emisión

- Transmisión 
- Recepción

En el desarrollo de esas tres operaciones se puede distinguir tres niveles:

- Psíquico

- Fisiológico

- Físico

Estos tres niveles están integrados dentro de un proceso que corresponde a un tipo social de relación, en el que se ha establecido un código definido y común: el idioma o lengua (Diez, 2011, pp.7-8).

LAS TICS + EL FEEDBACK; el impacto de las TIC "Tecnologías de la información", en la comunicación en las organizaciones, ha tomado un papel importante en la actualidad han abierto un abanico de posibilidades para la gestión de esa comunicación y ha supuesto una mejora en los flujos de comunicación dentro de la organización (Diez, 2006)., para Cacheiro (2018) la sociedad del conocimiento no es algo que exista actualmente, es más bien un ideal o una etapa evolutiva hacia la que se dirige la humanidad, la transmisión de información, en cualquier momento y a cualquier lugar. Se incluye dentro de este término a todos aquellos instrumentos electrónicos que permitan dicho procedimiento, con independencia del momento en el que dichos instrumentos fueron creados para interactuar con los públicos. El elemento clave con el que cuentan las empresas es la comunicación on-line, ya que gracias al desarrollo de la web 2.0, tienen a su disposición nuevas herramientas (los medios sociales) para llamar la atención de los stakeholders o grupos de interés e interactuar con los mismos (Pérez, Gómez, y Blanco, 2014).

La retroalimentación o feedback es fundamental en un proceso de comunicación porque es la información de regreso, la información que indica al emisor que el mensaje que ha emitido ha sido recibido; le indica si ha sido bien interpretado o no y si se ha utilizado.

La comunicación es lo que el receptor entiende, no lo que el emisor dice (Diez, 2011).

Branded content y transmedia: los planes de acción en el ámbito digital tienen que tener en cuenta que la comunicación estática, puramente promocional o de autobombo, no genera interacción con las comunidades de usuarios. Las audiencias están expuestas a múltiples impactos 
publicitarios en cualquiera de los formatos a los que puedan tener acceso (desde la televisión a redes sociales). Consecuentemente, cautivarlas (implicarlas) no es tan sencillo. Por esa razón, la comunicación debe aportar experiencias, contenido, calidad y entretenimiento. No es solo informar y persuadir. Es informar y entretener para persuadir.

El branded content: trata de generar contenidos de marca que sean atractivos para las audiencias. No es invasivo ni plano. Para ello, hay que profundizar en la identidad de la organización, en los públicos y en los medios con lo que se cuenta para poder establecer contenidos que aporten entrenamiento, conocimiento y cercanía sin renunciar a los valores de la marca. Los medios digitales permiten transmitir este tipo de contenidos, elaborados por la marca, de una manera asequible y transversal (Alard y Monford, 2017).

Hiperconectividad: Por cuanto hemos señalado hasta ahora, resulta indispensable en esta "era de la hiperconectividad" (Reig y Vílchez, 2013) encontrar un modo eficaz de gestionar la sobreabundancia informativa a la que diariamente se enfrentan los ciudadanos. De lo contrario, éstos corren el riesgo de no lograr digerir toda la información que consumen y, en último término, de ser incapaces de convertir dicha información en conocimiento (Serrano, 2013).

\section{REVISIÓN TEÓRICA}

\section{Una doble mirada}

El nuevo contexto tecnológico de hiperconectividad está cambiando la vida cotidiana, sus espacios y sus tiempos: la manera en la que las personas se comunican, se divierten, se forman, hacen gestiones burocráticas, cuidan de nuestra salud, viajan (...) En realidad, las personas están asistiendo a un verdadero cambio de época, en el cual, como en toda transformación, hay riesgos y hay oportunidades en muy distintos ámbitos. Van a cambiar - mejor, están cambiando ya y de forma acelerada - conceptos, estructuras y hasta instituciones poco menos que definitivas e inmutables.

Una transformación tan profunda - aunque no se percibe en toda su dimensión - necesariamente tiene un impacto complejo a todos los niveles que suscita muchas preocupaciones e interrogantes. La descripción de todo fenómeno complejo exige un análisis desde múltiples perspectivas. En este informe se ha seleccionado dos que parecen relevantes y 
complementarias: la del experto y analista de tendencias y la de los propios sujetos o actores. La creciente rapidez y aceleración de los cambios que se producen en el ámbito de las tecnologías de la información y la comunicación y su impacto social -con especial atención al mundo educativo- dificultan la capacidad de análisis y reflexión, así como la obtención de una visión de conjunto de lo que está ocurriendo y sus implicaciones (Reig y Vílchez, 2013, p. 16).

Una nueva era: la revolución tecnológica, en origen, como homínidos, la interacción, la comunicación entre individuos, se basaba en el lenguaje gestual, no verbal, acompañado de sonidos voluntarios de refuerzo. El posterior desarrollo del cerebro humano aumentó nuestra inteligencia, nuestra capacidad de reflexión, de imaginación y pensamiento. Con la aparición del lenguaje y de la escritura, la comunicación no solo se completa, sino que se convierte en una expresión total. Esa capacidad de juicio, abstracción y emoción pueden ser transmitidas por signos, palabras y letras. De forma oral y escrita (Lillo, 2015, p. 117).

\section{De la interacción a la Hiperconectividad en la CCS - UTB}

- Radios de la provincia y del cantón (anuncios sobre la carrera y sus avances), la carrera tendrá su espacio en la programación de los sábados al medio día, una vez por semana en el programa "Comunicándonos" participación activa de los estudiantes de la carrera de los últimos ciclos, supervisado por el docente de la materia a cargo del espacio.

- Buzón de sugerencias (referencia el código de cada estudiante para poder visualizar en qué está fallando la carrera en relación a lo que los estudiantes esperan en atención y avances de la facultad).

- Fanpage de la carrera de CS., con atención 9/9 (Community Manager-responsable del contenido).

- Cápsulas y posteo de contenido en Facebook Live de las prácticas académicas de los alumnos destacados en el espacio Comunicadores. CS-UTB. Extensión Quevedo. 
- WhatsApp office "Atención 9/9" (para informar, direccionar y gestionar las solicitudes de los señores estudiantes de la comunidad CS-UTB, sin tener que acudir al campus para algún requerimiento o consulta).

Figura 1. Hiperconectividad - CS UTB

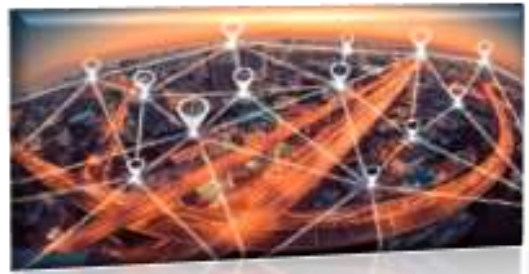

\section{Hiperconectividad - CS UTB}
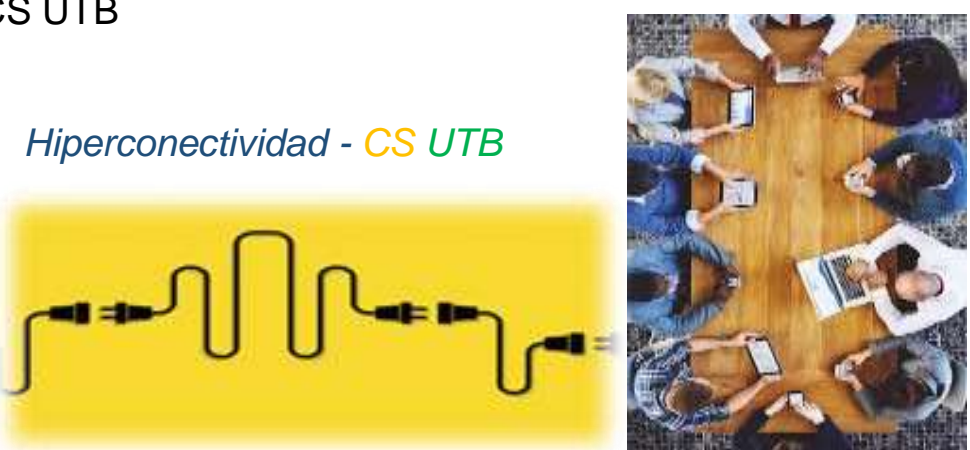

Fuente: Elaboración propia.

\section{Comunicación efectiva igual a Imagen corporativa}

\section{Matriz Comunicación Efectiva}

Figura 2. Como lograr que la comunicación sea efectiva a partir de Leyton (2018).

Establecer entorno
adecuado, libre de
elementos que perturben la
atención del receptor.

Claridad y concisión del
mensaje.

Evitar el exceso de la información. Para que la comunicación sea efectiva, debe ser lo más concisa posible.

Difusión permanente de la información, para que llegue a todos los miembros de la empresa.

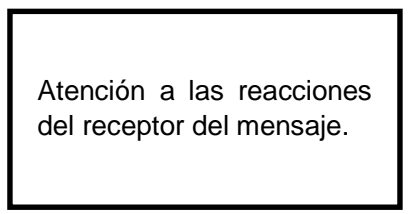

Lograr que la
comunicación rea
integrada. Debe de servir
de unión entre los
miembros de la empresa.

Utilización de términos que se adapten a la comprensión del oyente.
Aprovechamiento de los canales informales de comunicación para suplir las carencias de comunicación formal

Revisión perfeccionamiento constante de los canales de comunicación.

Fuente. Elaboración propia a partir de Leyton (2018). 


\section{Imagen Corporativa}

Es el resultado de la integración en la mente de los públicos con lo que la empresa se relaciona, de un conjunto de "imágenes" que, con mayor o menor protagonismo, la empresa proyecta hacia el exterior (Curras, 2010).

En la sociedad contemporánea, gran parte de la vida diaria se entrelaza con varias organizaciones: escuelas, oficinas públicas, instituciones religiosas, comercios, industrias, partidos políticos, asociaciones profesionales, hospitales, sindicatos, bancos, clubes sociales, etc. Las organizaciones constituyen fuentes de satisfacción (o frustración) de diversas necesidades económicas y sociales; vivimos inmersos en una sociedad organizacional (Collado, 2005).

\section{Remozamiento de marca}

Dar o comunicar un aspecto más lozano, nuevo o moderno de una marca al mercado (Hidalgo y otros, 2015).

\section{MATERIALES Y MÉTODOS}

El tipo de investigación es la descriptiva, en la cual se utilizó la encuesta como herramienta de investigación cuantitativa, a través de medios tradicionales como e-mail manual. El tamaño de la población fue de 430 estudiantes.

A continuación, se presenta el resultado de Muestra a estudiantes:

$$
\boldsymbol{n}=\frac{\boldsymbol{Z}^{2} * \boldsymbol{p} * \boldsymbol{q} * \boldsymbol{N}}{\boldsymbol{e}^{2} *(\boldsymbol{N}-\mathbf{1})+\mathbf{Z}^{2} * \boldsymbol{p} * \boldsymbol{q}}
$$

En donde:

$\mathrm{N}$ = tamaño de la población, 430

$Z=1.96$ al cuadrado (nivel de confianza 95\%)

$\mathrm{P}=$ probabilidad de éxito, o proporción esperada (en este caso $50 \%=0.5$ ) 
$Q=1-p($ en este caso 1-0.5 = 0.5)

$E=($ Error máximo admisible en términos de proporción $10 \%=0.1)$

$$
\begin{gathered}
n=\frac{(1.96)^{2} * 0.5 * 0.5 * 430}{(0.1)^{2} *(430-1)+(1.96)^{2} * 0.5 * 0.5} \\
n=\frac{3.8416 * 0.5 * 0.5 * 430}{0.01 *(430-1)+3.8416 * 0.5 * 0.5} \\
n=\frac{412,972}{4,29+0.9604} \\
n=\frac{412,972}{5,2504} \\
n=78,65
\end{gathered}
$$

\section{ANÁLISIS DE RESULTADOS}

Pregunta 1. ¿Se identifica Ud. con la carrera de Comunicación Social de la UTB?

Tabla 2. Identificación con la carrera de Comunicación Social.

\begin{tabular}{|c|c|c|}
\hline Respuesta & Cantidad & Porcentaje \\
\hline$S I$ & 71 & $89,87 \%$ \\
\hline NO & 8 & $10,13 \%$ \\
\hline Total & 79 & $\mathbf{1 0 0 \%}$ \\
\hline
\end{tabular}

Fuente: Elaboración propia. 
Gráfico 1. Identificación con la carrera de Comunicación Social.

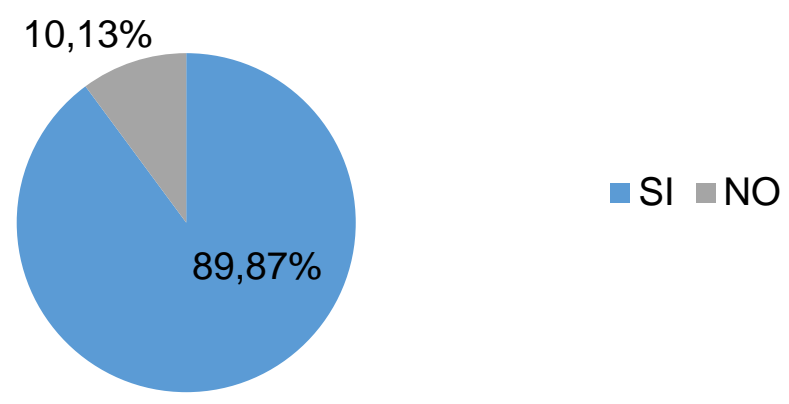

Fuente: Elaboración propia.

\section{Interpretación:}

En cuanto a la identificación de la carrera de Comunicación Social, se pudo identificar que se tiene un $89,87 \%$ de aceptación y un $10,13 \%$ que no se identifica con la misma, lo cual es un valor representativo importante de la carrera en los alumnos.

Pregunta 2. ¿Recomendaría Ud., la carrera de Comunicación Social a sus referidos?

Tabla 3. Recomendaría Ud. la carrera de Comunicación Social.

\begin{tabular}{|c|c|c|}
\hline Respuesta & Cantidad & Porcentaje \\
\hline SI & 70 & $88,61 \%$ \\
\hline NO & 9 & $11,39 \%$ \\
\hline
\end{tabular}




\begin{tabular}{|c|c|c|}
\hline Total & 79 & $100 \%$ \\
\hline
\end{tabular}

Fuente: Elaboración propia.

Gráfico 2. Recomendaría Ud. la carrera de Comunicación Social.

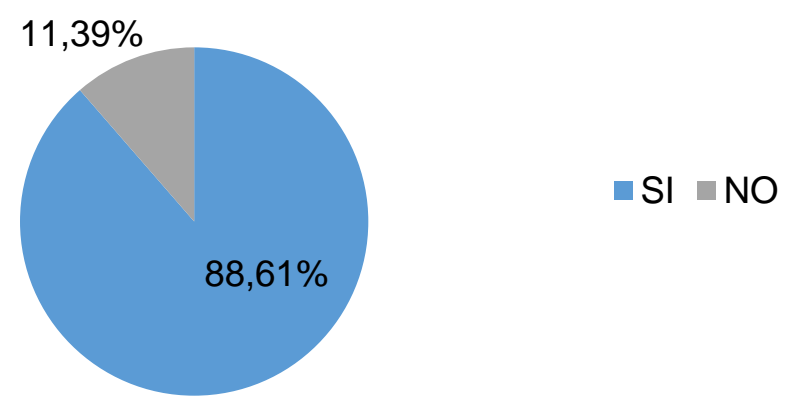

Fuente: Elaboración propia.

\section{Interpretación:}

En cuanto a la recomendación de la carrera de Comunicación Social, los entrevistados lo consideran relevante con un $86,61 \%$ indicando que si la recomendarían y un $11,39 \%$ no lo haría. Los alumnos tienen el sentido de pertenencia y eso los convierte en referentes para que el posicionamiento de la carrera y el marketing boca a boca se de en una forma positiva especialmente en la provincia de Los Ríos.

Pregunta 3. ¿Está de acuerdo Ud., con los canales comunicacionales que utiliza la carrera de Comunicación Social actualmente, para informar sobre actividades y eventos? 
Tabla 4. Canales utilizados en la carrera de Comunicación Social.

\begin{tabular}{|c|c|c|}
\hline Respuesta & Cantidad & Porcentaje \\
\hline SI & 63 & $79,75 \%$ \\
\hline NO & 16 & $20,25 \%$ \\
\hline Total & 79 & $\mathbf{1 0 0 \%}$ \\
\hline
\end{tabular}

Fuente: Elaboración propia.

Gráfico 3. Canales utilizados en la carrera de Comunicación Social.

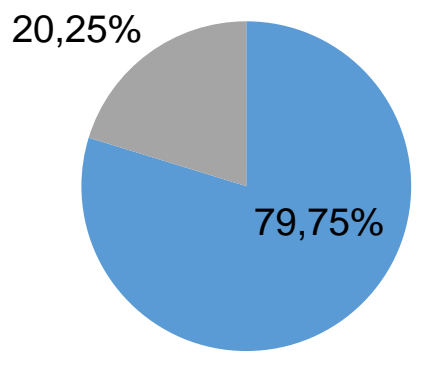

$\sim \mathrm{SI} \sim \mathrm{NO}$

Fuente: Elaboración propia.

\section{Interpretación:}

En cuanto a la Aceptación de los medios de comunicación utilizados, los entrevistados lo consideran relevante con un $79,75 \%$ el cual lo evalúan como aceptables, y un $20,25 \%$ lo evalúan como no aceptables. 
Pregunta 4. ¿Considera Ud. las App. como un medio necesario para difundir y compartir las actividades y gestiones que se dan en la carrera de Comunicación Social?

Tabla 5. Considera las App. como un medio necesario para difundir las actividades de la carrera.

\begin{tabular}{|c|c|c|}
\hline Respuesta & Cantidad & Porcentaje \\
\hline SI & 72 & $91,14 \% \%$ \\
\hline NO & 7 & $8,86 \%$ \\
\hline Total & 79 & $\mathbf{1 0 0} \%$ \\
\hline
\end{tabular}

Fuente: Elaboración propia.

Gráfico 4. Considera las App. como un medio necesario para difundir las actividades de la carrera.

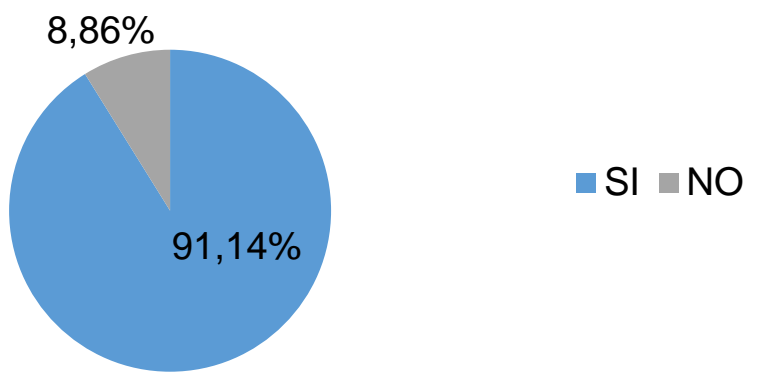

Fuente: Elaboración propia.

\section{Interpretación:}

En cuanto al manejo de las App como un medio necesario de difusión, los entrevistados lo consideran relevante con un $91,14 \%$, el cual lo evalúan como necesario y un $8,86 \%$ lo valoran 
como no indispensable. En la actualidad las App, son el canal directo para mejorar la experiencia entre la marca CCS UTB - extensión Quevedo y los señores estudiantes.

Pregunta 5. ¿Le gustaría informarse de las actividades y eventos de la carrera de Comunicación Social por medio de canales digitales?

Tabla 6. Informarse a través de medios digitales.

\begin{tabular}{|c|c|c|}
\hline Respuesta & Cantidad & Porcentaje \\
\hline SI & 73 & $92,41 \%$ \\
\hline NO & 6 & $7,59 \%$ \\
\hline Total & 79 & $\mathbf{1 0 0 \%}$ \\
\hline
\end{tabular}

Fuente: Elaboración propia.

Gráfico 5. Informarse a través de medios digitales.

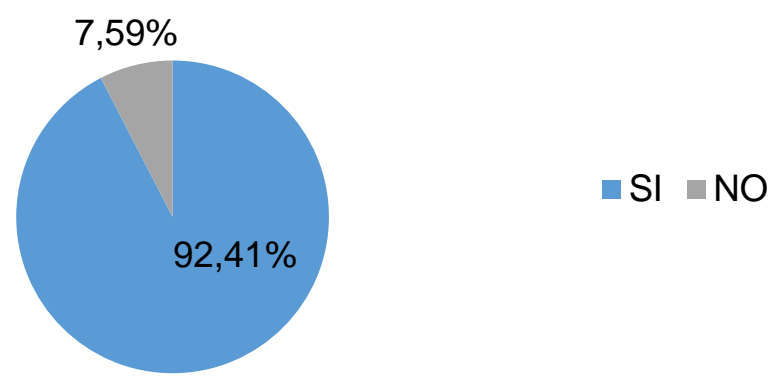

Fuente: Elaboración propia. 


\section{Interpretación:}

En cuanto a informarse a través de medios digitales la población encuestada manifestó en un $92,41 \%$ estar de acuerdo y tan solo un $7,59 \%$ que no.

Pregunta 6. ¿Qué medios digitales Ud., utiliza con mayor frecuencia?

Tabla 7. Medios digitales utilizados con frecuencia.

\begin{tabular}{|c|c|c|c|}
\hline \multicolumn{2}{|c|}{ Respuesta } & Cantidad & Porcentaje \\
\hline \multirow{2}{*}{ FACEBOOK } & SI & 75 & $94,94 \%$ \\
\cline { 2 - 4 } & NO & 4 & $5,06 \%$ \\
\hline \multirow{2}{*}{ INSTAGRAM } & SI & 20 & $25,32 \%$ \\
\cline { 2 - 4 } & NO & 59 & $\mathbf{7 4 , 6 8 \%}$ \\
\hline \multirow{2}{*}{ WHATSAPP } & SI & 79 & $100 \%$ \\
\cline { 2 - 4 } & NO & 0 & $0 \%$ \\
\hline Total & & $\mathbf{7 9}$ & $\mathbf{1 0 0} \%$ \\
\hline
\end{tabular}

Fuente: Elaboración propia. 
Gráfico 6. Medios digitales utilizados con frecuencia.

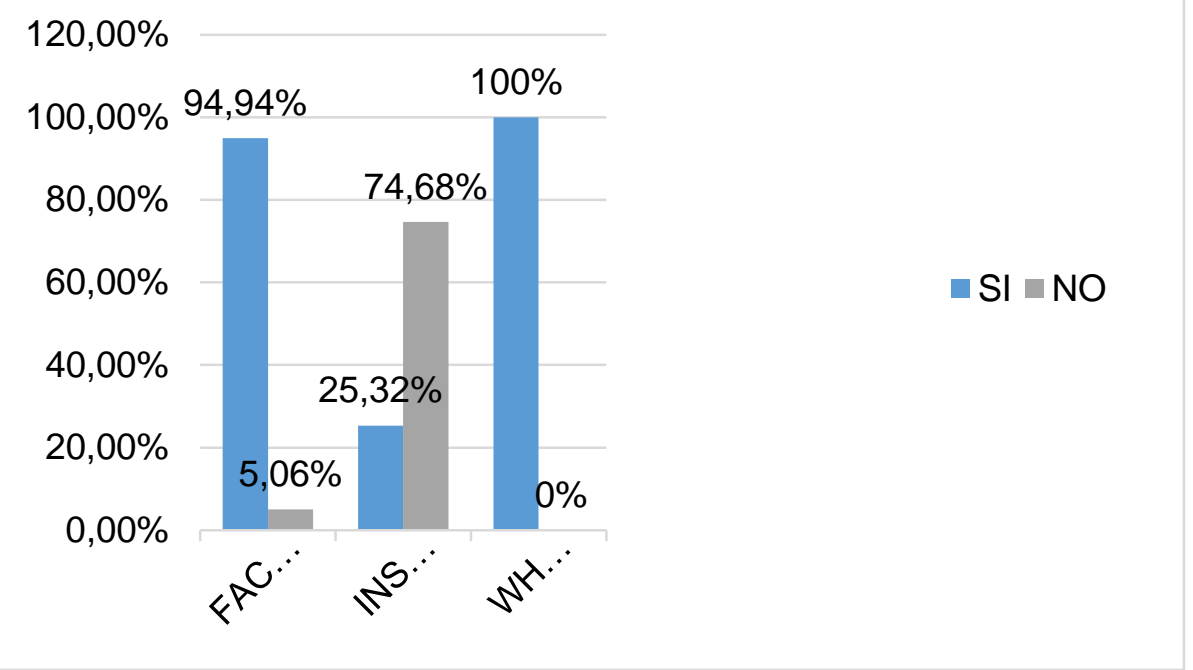

Fuente: Elaboración propia.

\section{Interpretación:}

En cuanto a los medios utilizados con frecuencia entre la población encuestada tenemos las valoraciones que un $94,94 \%$ usa Facebook y apenas 5,06\% no lo usa. Instagram lo utilizan un $25,32 \%$ y un $74,68 \%$ no lo usa. WhatsApp lo utiliza un $100 \%$ de la población encuestada.

Entre las valoraciones cualitativas predominantes, están: la comunicación horizontal entre ellos, y la vertical, tanto descendente como ascendente.

La universidad Técnica de Babahoyo extensión Quevedo, en base a la investigación y análisis científico se crea la necesidad de diseñar una matriz estratégica de comunicación efectiva la cual hace referencia en el siguiente gráfico.

\section{Matriz Estratégica de Comunicación Efectiva}


Figura 3. Modelo estratégico de comunicación efectiva.

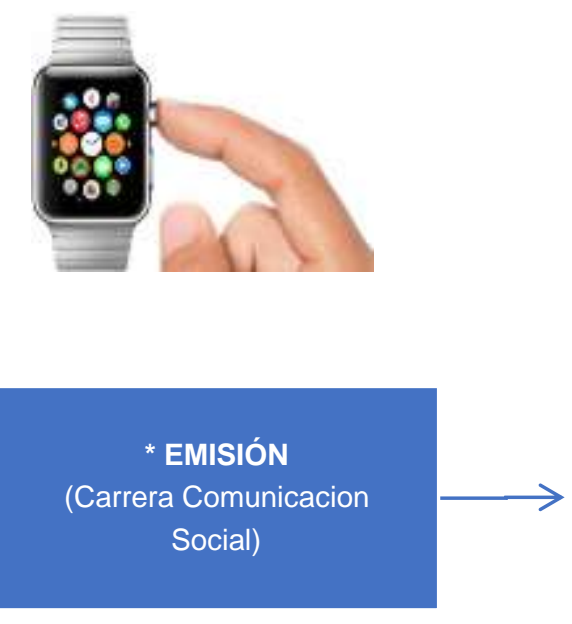

\section{‘ DIFUSIÓN \\ Comunidad Universitaria \\ Usuarios \\ (Los medios y herramientas que utilizo para informar sobre mis actividades)}

*Retroalimentación

(Medios de ejecusión)

"Entorno

(Circulo social donde apunto mis estr@tegi@s)

*Plataformas sociales:

(linkeding, instagram, whatsApp

academico, facebook, emails-intranet)
* RECEPCIÓN

Imagen

Reputación

Públicos - usuarios

(internos - externos)

Fuente: Elaboración propia.

Fortalecer la imagen de la carrera de CC-UTB, Extensión Quevedo, haciendo presencia digital, con links desde la página web de la Universidad Técnica de Babahoyo, para generar tráfico y mantener un acercamiento directo con los públicos (internos y externos) para seguir trabajando en la mejora continua, que busca la excelencia académica de la comunidad de la carrera de Comunicación Social UTB Extensión Quevedo.

\section{CONCLUSIONES}

La carrera de Comunicación Social de la Universidad Técnica de Babahoyo extensión Quevedo, cuenta con un buen posicionamiento ante los estudiantes, se sienten identificados con la misma; sin embargo, las tendencias actuales del mercado de la era digital, apuntan a que la carrera tiene que innovar y comunicar más sobre las actividades y eventos, mejorar la experiencia y la razón de ser que significa ser un comunicador en tiempo real. 
Los alumnos entrevistados en un $91.14 \%$ reflejaron en el resultado de las encuetas realizadas, estar de acuerdo con que las App., son el medio apropiado para informar y difundir todo lo concerniente a las actividades académicas y eventos de la carrera de CS, dando esto como antecedente que la investigación realizada confirma la falta de medios digitales en la actualidad entre la marca CS UTB con los estudiantes y lo indispensable que sería contar con su uso.

Se diseñó un plan estratégico de hiperconectividad, bajo la temática: aun clip de distancia, para que sea ejecutado a partir del primer semestre del año 2020, con el cual se reposicionará la Marca CCS-UTB, el cual inicia con el lanzamiento oficial de la identidad visual de la Carrera de Comunicación Social UTB, en las respectivas App., como parte de la estructura de la estrategia de comunicación efectiva, la cual permitirá que los usuarios-alumnos y prospectos se identifiquen con el modelo del perfil del comunicador 2035, que requerirán las organizaciones en un mundo cada segundo más digitalizado.

\section{REFERENCIAS BIBLIOGRÁFICAS}

Alard, J. \& Monford, A. (2018). Plan de comunicación on y off en la práctica. Bogotá. Consejo de aseguramiento de la calidad de la educación superior. Recuperado de https://www.caces.gob.ec/

Currás, R. (2010). Identidad e imagen corporativas: revisión conceptual e interrelación. Revista Científica Teoría y Praxis. ISSN 1870-1582, No. 7, pp. 9-34. Recuperado de https://dialnet.unirioja.es/servlet/articulo?codigo=3233182

Diez, S. (2011). Técnicas de Comunicación. Bogotá, Colombia: Ediciones de la U.

Reig, D. y Vilchez, L.F. (2013). Los jóvenes en la era de la hiperconectividad: tendencias, claves y miradas. Madrid: Fundación telefónica y Fundación Telefónica y Fundación Encuentro, p. 212

Hidalgo, Ch. y Mora. (2015). Estudio de caso: El remozamiento de la identidad visual corporativa del Banco Guayaquil en Ecuador. Revista científica Razón y palabra. Recuperado de www.razonypalabra.org.mx 
Lillo, J. (2015). Los $360^{\circ}$ de la comunicación. Bogotá: Ediciones de la Universidad Técnica de Babahoyo. Recuperado de https://www.utb.edu.ec/

Pérez, C., Gómez, J. y Balnco, J. (2014). La comunicación empresarial en la Web. 2.0. Estrategias para la gestión efectiva de la reputación corporativa. Revista Tecnológica Ciencia y Educación. Recuperado de http://www.revistasocitec.org/index.php/TCE/article/view/33/20

Serrano, J. (2013). Una propuesta de dieta digital: Repensando el consumo mediático en la era de la hiperconectividad. ISSN: 2172-9077 